\title{
La experiencia de la guerra en la pantalla: el desembarco en la playa de Omaha de Saving Private Ryan
}

\section{Julio Montero-Díaz ${ }^{1}$ \\ Laura Fernández-Ramírez ${ }^{2}$}

Recibido: 2014-05-19

Enviado a pares: 2014-05-19
Aprobado por pares: 2014-07-09

Aceptado: 2014-07-19

DOI: 10.5294/pacla.2015.18.1.4

Para citar este artículo / To reference this article / Para citar este artigo

Montero-Díaz, J., Fernández-Ramírez, L. Marzo de 2015. La experiencia de la guerra en la pantalla: el desembarco en la playa de Omaha de Saving Private Ryan. Palabra Clave 18(1), 83-110. DOI: 10.5294/pacla.2015.18.1.4

\section{Resumen}

El cine de Hollywood ha dado un testimonio informal de las guerras, particularmente de la Segunda Guerra Mundial. Saving Private Ryan (Steven Spielberg, 1998) rompió el modelo naturalista y romántico del subgénero. Se basó en el testimonio de los veteranos de guerra y se orientó no hacia el desarrollo de una operación bélica, sino a la reproducción hiperrealista del combate y la cotidianidad de la guerra. Dio forma audiovisual a una memoria y experiencia individuales, las del veterano, que habitualmente no habían tenido cabida en el relato institucional de la guerra o en su reflejo cinematográfico anterior. Este artículo presenta un análisis estilístico de su secuencia más aplaudida por su efecto y valor artístico: el desembarco en la playa de Omaha. Atiende a la descripción de sus recursos de planificación, sonido y montaje. Muestra que, a través del recurso a técnicas estilísticas

1 Catedrático de Historia de la Comunicación Social de la Universidad Complutense de Madrid. España. jumondi@ccinf.ucm.es

2 Profesora de Realización, Videocreación y Diseño Digital de la Universidad de Burgos. España.

laurafdezramirez@gmail.com 
expresivas formuladas por S. M. Eisenstein, la secuencia busca introducir al espectador en el combate, hacerle participar de las sensaciones y razonamientos del soldado -en este caso el capitán Miller-, y lograr así su inmersión en la acción bélica, su compromiso con él y la comprensión del origen de su trauma. Para ello se ha recurrido a una vía de análisis inspirada en el proceso metodológico que S. M. Eisenstein empleaba en dos de sus artículos para explicar el valor del planteamiento estilístico de El acorazado Potemkin (1925) a sus detractores. Consiste en la descripción del esquema expresivo que configura el diseño de planos y fragmentos de montaje y su comparación con los que los preceden o suceden. Mediante esta metodología dialéctica, se describe el estilo general de la secuencia y sus pretensiones expresivas, así como se localizan momentos de contraste y ruptura que acusan su servicio a un motivo emocional: traducir el trauma del combatiente.

\section{Palabras clave}

Cine, filmación, película histórica, análisis cualitativo (Fuente: Tesauro de la Unesco). 


\section{The Experience of War on the Screen: The Landing at Omaha Beach in Saving Private Ryan}

\section{Abstract}

Hollywood cinema has given informal testimony to war, particularly World War II. Saving Private Ryan, a 1998 war film directed by Steven Spielberg, broke the naturalist and romantic model of this sub-genre. Based on the testimony of veterans, it is not a film about the development of a military operation; instead, it is a hyperealistic reproduction of combat and the daily rigors war. It gives audiovisual form to the individual memory and experience of veterans, who were not usually part of the institutional account of the war and its earlier portrayals on the silver screen. This paper offers a stylistic analysis of the sequence in Saving Private Ryan that is most applauded for its effect and artistic value: the D-Day landing on Omaha Beach. It describes the resources used in its planning, sound and editing. It shows how the expressive stylistic techniques shaped by S.M. Eisenstein are used to involve the film's audience in the fighting and in the feelings and reasoning of the soldier; in this case, Captain Miller. In the end, it manages to immerse the audience in the war, securing its commitment to the soldier, and enabling it to understand the source of his trauma. The analysis uses the method S.M. Eisenstein employed in two of his articles to convince his detractors of the value of the stylistic approach used in Battleship Potemkin (1925). It consists of a description of the expressive scheme behind the design of the shots and the fragments in the montage, and a comparison to those that precede or follow them. The overall style of the sequence and its expressive intentions are explained by way of this dialectical method, which also is used to pinpoint the moments of contrast and rupture that serve an emotional motive; namely, to translate the soldier's ordeal.

\section{Keywords}

Film, filming, historical film, qualitative (Source: Unesco Thesaurus). 


\section{A experiência da guerra na tela: o desembarque na praia de Omaha de Saving Private Ryan}

\section{Resumo}

O cinema de Hollywood tem dado testemunho informal das guerras, particularmente da Segunda Guerra Mundial. Saving Private Ryan (Steven Spielberg, 1998) rompeu com o modelo naturalista e romântico do subgênero. Baseou-se no depoimento dos veteranos de guerra e orientou-se não em direção do desenvolvimento de uma operação bélica, mas sim da produção hiper-realista do combate e da cotidianidade da guerra. Deu forma audiovisual a uma memória e experiência individuais, as do veterano, que habitualmente não tinham tido espaço no relato institucional da guerra ou em seu reflexo cinematográfico anterior. Este artigo apresenta uma análise estilística de sua sequência mais aplaudida por seu efeito e valor artístico: o desembarque na praia de Omaha. Atende à descrição de seus recursos de planificação, som e montagem. Mostra que, por meio do recurso a técnicas estilísticas expressivas formuladas por S. M. Eisenstein, a sequência busca introduzir o espectador no combate, fazê-lo participar das sensações e raciocínios do soldado - nesse caso o capitão Miller-, e conseguir assim sua imersão na ação bélica, seu compromisso com ele e a compreensão da origem de sua trama. Para isso, recorreu-se a uma via de análise inspirada no processo metodológico que S. M. Eisenstein empregava em dois de seus artigos para explicar o valor do pensamento estilístico de $O$ Encouraçado Potemkin (1925) a seus detratores. Consiste na descrição do esquema expressivo que configura o desenho de planos e fragmentos de montagem e sua comparação com os que os precedem ou sucedem. Mediante essa metodologia dialética, descreve-se o estilo geral da sequência e suas pretensões expressivas, bem como se localizam momentos de contraste e ruptura que acusam seu serviço de um motivo emocional: traduzir o trauma do combatente.

\section{Palavras-chave}

Cinema, filmagem, filmehistórico, análise qualitativa (Fonte: Tesauro da Unesco). 


\section{Introducción}

La crónica de las guerras ha constituido, durante siglos, el núcleo esencial de la historia. Así, "la voluntad o el deseo de un grupo social de seleccionar y organizar las representaciones del pasado de tal modo que los individuos la asuman como propia" (Wood, 1999, citado en Cole, 2002: 130) ha conformado imaginarios y sentimientos en torno a la identidad nacional que han definido la memoria colectiva de una guerra.

Frente al modo institucional de narrar la guerra hay otro más informal, propio de las conversaciones entre camaradas de armas. Su escenario son los encuentros de veteranos, en donde intentan perpetuar de algún modo su memoria y experiencia individuales. En el testimonio de los excombatientes lo anecdótico adquiere categoría de referente.

Estos recuerdos de la guerra son muchas veces traumáticos, reviven el sentimiento de culpa tras sobrevivir a tantos otros (Bourke, 2004: 483). A muchos, ciudadanos reclutados o voluntarios, no los entrenaron para asimilar el terror y la culpa que lleva años suprimir en soldados profesionales; ellos, en pocas semanas debían abandonar los principios y comportamientos propios de un civil y adoptar los del soldado (Leed, 2000: 88). El trauma se oculta: "mi familia no sabe nada de eso... son cosas de las que no hay que hablar" (Cowen, 2001). Para el veterano, solo un compañero de armas puede entenderlo y darle sentido, por haber compartido los mismos referentes vividos. Por ello rechazan la visión heroica de su hazaña difundida por el relato institucional que contradice su propia valoración de sus acciones (Cole, 2002: 132). El relato institucional de su guerra se percibe generalmente como algo que "invade el recuerdo individual, que crea silencio en lugar de comunicación. ( ... La memoria pública (...) generalmente contradice su recuerdo individual hasta el punto de considerarse inauténtica" (Lagrou, 2000: 305).

Pese al valor histórico del recuerdo de la guerra de los que la vivieron efectivamente, tras cada conflicto bélico el relato conmemorativo ha adquirido mucha más importancia que el de su experiencia personal o el de su efecto traumático (Bourke, 2004: 481). El testimonio traumático del veterano 
solo se incluye en el relato institucional cuando sirve "a los objetivos sociales o políticos de importantes grupos sociales” (Bourke, 2004: 473). Este contraste y escisión entre su testimonio y la visión oficial de la guerra ha hecho preciso acudir a sus recuerdos para completar el relato de la historia de las guerras (Bourke, 2004: 485). Y lo mismo ha sucedido en su versión cinematográfica.

Hollywood ha presentado también un testimonio informal de las guerras, especialmente de la Segunda Guerra Mundial. Su reflejo durante el periodo clásico ofrecía una visión de la contienda muy similar a la de la historiografía tradicional. Salvo en casos excepcionales, las dificultades de los veteranos al volver a casa traumatizados no tenían cabida (Schatz, 2002: 759). Hollywood presentaba un relato triunfalista, una crónica de la guerra en tercera persona. Las películas clásicas sobre la Segunda Guerra Mundial conformaron un modelo de reproducción naturalista y romántico, motivado por la composición de héroes y villanos y la exposición clara del desarrollo de la contienda o una misión particular (Basinger, 1986). El subgénero de combate clásico fue el principal modo en el que los civiles que no tenían experiencia directa de la guerra conformaban su imagen de esta (Wetta \& Novelli, 2003: 863). Se ha señalado con frecuencia que no permitía comprender la vivencia terrorífica y traumática que supone una guerra.

No es posible realizar una verdadera película de guerra. Lo más próximo que se me ocurre a una película bélica del todo auténtica es introducir a dos hombres armados tras la pantalla del cine para que en el momento del combate disparen al patio de butacas (...) Ir a la película y ser herido. Sólo así se puede hacer una película legítima sobre lo que supone la experiencia de una guerra (citado en Basinger, 1994: 168).

Saving Private Ryan (Steven Spielberg, 1998 -en adelante SPR-) supuso un cambio radical en el subgénero y se convirtió en el nuevo modelo de cine bélico hasta hoy (Biesecker, 2002; Klien, 2005; Gates, 2005). Su representación hiperrealista del combate, su vinculación con el proceso de memoria -la película es el flashback de un veterano-y su reproducción de la experiencia traumática del combatiente la convirtió en "la primera en refle- 
jar de un modo auténtico el horror de la batalla, especialmente la secuencia del desembarco en la playa de Omaha” (Bodnar, 2001: 805).

Para Spielberg las representaciones clásicas de la Segunda Guerra Mundial "trataban absolutamente todo respecto a la guerra, menos lo que suponía verdaderamente estar ahí” (citado en Hasian, 2001: 347). Así, el planteamiento innovador de su película, por su foco en la memoria y experiencia individuales, causó tal impresión en los excombatientes "que salían aturdidos, alucinados, emocionados en silencio" (Cohen, 1999: 35). Tanto que el ejército debió poner en marcha una línea de ayuda al veterano (Hasian, 2001: 339). Los que no vivieron el conflicto bélico decían: "me metí por un momento en los zapatos de mi padre. Me encontré verdaderamente allí, y creo que ahora entiendo mucho mejor por qué sufría tanto cuando hablaba de lo que pasó en la playa de Omaha" (citado en Hasian, 2001: 346). SPR "logró reconciliar a dos generaciones" (Ambrose, 1998: 59), a los baby boomers y la generación $\mathrm{X}$, cuya visión de la guerra se había configurado a partir de la experiencia directa o indirecta de la guerra de Vietnam y otros conflictos como el de Mogadiscio de 1993, con las vivencias de la gran generación. Su fundamento en entrevistas a los excombatientes aportó al espectador una visión de la cotidianidad y del sacrificio del soldado que le había sido negada por el relato institucional de la historia o su versión cinematográfica anterior. Posibilitó "un nuevo teatro de operaciones de la memoria histórica traumática en el cine" (Walker, 2004: 131) e invitó a la opinión pública a reconsiderar su visión crítica previa de las instituciones y operaciones militares, al identificarla emocionalmente con el soldado (Sugimoto, 2000: 645).

SPR originó un ciclo bélico en el que la fidelidad y el protagonismo de la evolución de la contienda pierde importancia ante la reproducción de la experiencia del combatiente: como en el relato histórico informal de los veteranos. Largometrajes como SPR, Letters from Iwo Jima y Flags of Our Fathers (Clint Eastwood, 2006) o series televisivas como Band of Brothers (Hanks \& Spielberg, 2001) presentan a personajes contemporáneos que reconstruyen a partir de sus recuerdos lo que debió ser la experiencia de los soldados. Los relatos los focaliza un testigo que relata recuerdos (propios o ajenos) y 
revive las experiencias y sensaciones en su memoria (Pérez, 2012). Se evita "una mera reflexión de orden político" (Muruzábal \& Grandío, 2009: 66). Se personaliza y humaniza por la reproducción de la memoria y experiencia individuales. Esto permite "conectar" con el espectador de hoy, incluso con el crítico, al hacerle experimentar vicariamente las sensaciones de los protagonistas del pasado. Aunque jamás hayamos combatido nos convierten en compañeros de armas y nos sitúan entre ese núcleo de hombres que pueden entender qué es vivir la guerra.

El cambio fundamental de SPR no fue narrativo. En la cinematografía contemporánea lo que atrapa al espectador no es el diálogo o los momentos introspectivos, sino "el tamaño, la frecuencia y la intensidad sobrecogedora de sus secuencias de espectáculo” (King \& Krzywinska, 2002: 16). El desarrollo narrativo se ve mermado por la construcción de una experiencia "más vívida e intensa que la fundada en observar la realidad en términos exclusivamente realistas” (King, 2000/2009). En esta línea, la reproducción del combate en SPR no se orienta exclusivamente hacia la verosimilitud propia del modelo canónico, sino hacia la expresividad. Se busca componer algo intangible, imposible de representar mediante imágenes exclusivamente realistas: cómo fue "haber estado allí", cómo se siente uno inmerso en una batalla.

Se busca la participación vicaria del espectador y su compromiso emocional y moral con el soldado. La expresividad de su enunciación construye la dimensión interna del combatiente. Así, cualquier tipo de espectador puede por fin comprender las "batallitas del abuelo", porque se convierte en un compañero de armas que comparte lo que se siente al luchar. Convertido en un "habitante de la imagen" (Stam, 2001: 362), puede "vivir" la guerra aunque jamás haya participado en una.

El tratamiento audiovisual del cine bélico, y en particular de $S P R$, se ha tratado poco en los estudios académicos (Winter, 2001: 863), que han atendido más a la fidelidad a los hechos o al análisis narrativo o retórico, o de relación de su mensaje con el contexto de producción (Muruzábal, 2007: 1-2). Muchos particularizan en los recursos narrativos que articulan 
la memoria individual o el trauma del combatiente (Sugimoto, 2000; Hasian, 2001; Bodnar, 2001; Auster \& Quart, 2002; Biesecker, 2002; Ehnrenhaus, 2002; Pérez, 2012), pero no atienden específicamente a las estrategias audiovisuales empleadas para este fin.

Aquí, se pretende definir cuáles son las estrategias de planificación, sonido y montaje que buscan la inmersión del espectador en el combate, para conseguir el compromiso emocional y moral con el soldado y participar así de la experiencia traumática que supone vivir una guerra. $Y$ eso en un ejemplo concreto, $S P R$, y en una secuencia particular: el desembarco en la playa de Omaha.

Teóricos del cine de espectáculo contemporáneo -que incluye el cine bélico- detectan que los cineastas norteamericanos hacen uso de las técnicas de planificación y montaje de S. M. Eisenstein en sus secuencias de acción (Stam, 2001; Dancyger, 2007; King, 2009). Algunos de ellos reconocen abiertamente su influencia:

Teníamos el montaje clásico y el montage eisensteniano, y esto se
podía llevar más allá. El cine americano ha absorbido todas las téc-
nicas de los soviéticos y ahora están en nuestro cine. La verdad es
que muchas de estas técnicas han sido apropiadas y son parte de
lo que hacemos los montadores de Hollywood cuando trabajamos
en películas de acción. Porque nosotros también queremos provo-
car reacciones en el público. Queremos que salten del asiento, que
la experiencia no resulte cómoda. Pero no para llevarlos a la Revolu-
ción, sino para que de verdad disfruten de la película (Goldblatt, en
Apple, 2004).

Este artículo plantea que, para lograr una sensación fisiológica de la guerra, reproducir el trauma del soldado -en este caso el del capitán Miller, interpretado por Tom Hanks- y lograr que el espectador se comprometa con él y participe de sus sensaciones y razonamientos, la secuencia elegida de SPR utiliza algunas de las estrategias estilísticas de S. M Eisenstein: en concreto los "esquemas", la "colisión lógica" y un diseño audiovisual heterogéneo y tendencioso, definido por un "motivo" emocional. 


\section{Materiales y metodología}

Eisenstein en sus indagaciones teóricas quiso establecer los recursos fílmicos que permiten condicionar una respuesta del espectador, conseguir que la película afecte sus emociones y su modo de considerar ideológicamente la realidad (1934/1999: 57-71). Su planteamiento -aquí se resume escuetamente por falta de espacio- giraba en torno a la necesidad de que la forma de un cuadro, o el montaje de una secuencia, se definiera formalmente de un modo tendencioso adecuado a la finalidad que buscaba el artista, tal y como el orador escoge y ordena las palabras para conseguir un efecto concreto en su público. El diseño audiovisual de un filme debía estar al servicio de un motivo emocional o temático -también denominado "dominante" De este modo el estilo de un filme contribuía a la construcción de sentido, y no sólo a la reproducción naturalista de la realidad ficcional (Eisenstein, 1924). Así, "la obra se conformaría de la manera más adecuada para que el público comprendiera su mensaje” (Sánchez-Biosca, 1996: 108).

Para lograrlo, es preciso organizar los elementos de un cuadro o de un fragmento según esquemas de composición y montaje, lo suficientemente generales y comprensibles por el público, que permitan al cineasta subrayar el valor específico de un plano o escena: su motivo (1937:37). La colisión entre planos o fragmentos - el contraste, ya sea en sus contenidos, su naturaleza, tratamiento estilístico o disposición estructural o rítmica- permite que la combinación de imágenes de elementos procedentes de la realidad con un significado inalterable pueda producir una metáfora significante: que transmita una idea o emoción implícita (Eisenstein, 1929/1999).

Para defender este planteamiento ante sus detractores, partidarios del realismo socialista, Eisenstein redactó dos artículos, "Ellenguaje cinematográfico" (1934) y "La unidad orgánica y lo patético en El acorazado Potemkin" (1939), que muestran cómo la configuración heterogénea y tendenciosa de un texto, construido estilísticamente mediante esquemas y colisiones, permite una comunicación más completa y compleja con el espectador que si su diseño solo sirve para presentar de modo realista el contenido. En ellos analiza escenas de El acorazado Potemkin (1925) como ilustración. Desde esta base se aborda el análisis de la secuencia elegida de SPR. 
En el primer texto muestra el motivo de los cuadros de una secuencia a partir de las diferencias cualitativas entre los esquemas compositivos que se emplean. Describe un cuadro a partir de su comparación con las características del anterior y desvela la respuesta que la sucesión de los mismos pretende en el público. Aumont y Marie valoran este sistema de análisis dialéctico para el estudio posestructuralista o semiopragmático de un texto (1990: 26-33). En el segundo artículo, Eisenstein proyecta esta vía al análisis de la configuración de los fragmentos. Subraya cómo los esquemas de montaje -tendenciosos-y las colisiones entre ellos contribuyen a la comprensión del subtexto de la obra. Aquí se plantea que esta vía que atiende a la lectura dialéctica de planos y fragmentos de montaje es válida para definir el sistema estilístico de un texto y para sugerir la misión comunicativa de cada una de sus estrategias, aunque se parta de un sistema analítico y en parte naturalista, como en el caso de la película seleccionada. No se trata de hallar lo que hipotéticamente el autor pretende con su diseño, sino lo que la enunciación del propio texto señala o exige del espectador (aunque su respuesta sea imposible de determinar en términos absolutos).

La obra teórica de Eisenstein "constituye una forma más sistemática de constructivismo teórico que todavía no ha sido rebasada por la teoría fílmica, a pesar de las aventuras conceptuales de la semiótica textual, la narratología y el cognitivismo" (Sánchez-Biosca, 1996: 119). Esto apoya nuestra apuesta por desarrollar en este artículo su vía de análisis dialéctico para el estudio cualitativo de la forma del discurso. Si sus técnicas de planificación y montaje efectivamente se emplean en la actualidad -dentro del sistema analítico tradicional de Hollywood-, resulta lógico recurrir a su sistema para estudiarlas. No obstante, Eisenstein no dejó escrito alguno en el que explicara su proceso metodológico. Por ello se ha debido desarrollar aquí tras estudiar el que emplea en los artículos citados.

El proceso ha sido el siguiente: se ha capturado la secuencia mediante un programa de edición informático, se ha fragmentado según los cortes que contiene, se ha tomado una imagen del primer fotograma de cada cuadro, que sirve como referencia para el análisis de este y para detectar el esquema empleado para su configuración. Es una imitación del uso de 
storyboards de Eisenstein en su primer artículo. También se ha tomado una imagen del timeline de la secuencia, dividida en fragmentos o escenas que se identifican con una letra, según los cambios de esquema estructural o rítmico detectados (figura 1). Así se simplifica el sistema de Eisenstein empleado en el segundo artículo para analizar el ritmo (mediante fracciones matemáticas, aquí se aprecia a partir de una imagen).

\section{Figura 1}

\section{Escena A}

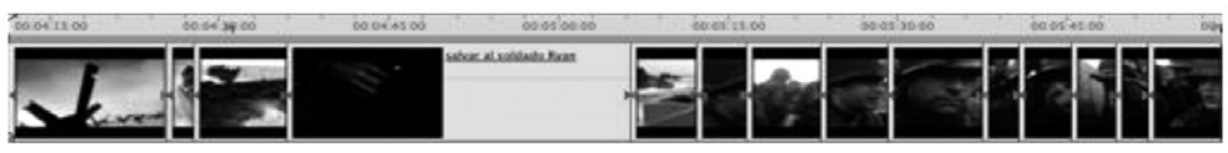

Finalmente, el análisis ha consistido en el estudio fragmento a fragmento y cuadro a cuadro de la secuencia. Se atiende específicamente a los esquemas empleados y a las diferencias estilísticas existentes entre los sucesivos. Después se ha procedido a interpretar la finalidad de la configuración de cada elemento según su uso previo en la secuencia o normas de composición cinematográficas generales. Para articular los resultados que se exponen a continuación se han agrupado los esquemas y tipos de colisiones más habituales en la secuencia según su misión comunicativa o la respuesta que exigen del espectador.

\section{Resultados del análisis}

La secuencia presenta dos combates: uno histórico y uno íntimo. Se distinguen por tener tratamientos estilísticos diversos. Unos esquemas compositivos y de montaje sitúan al espectador en un lugar físico en el combate. Es más, le transmiten la misma sensación fisiológica que un soldado en Omaha bajo el fuego enemigo. Otros esquemas transmiten la batalla emocional que libra Miller, en la que combaten su "yo" civil y su deber militar. Además, esquemas específicos señalan como subtexto de la secuencia el origen del trauma del capitán: el sentimiento de culpa por la muerte de compañeros y enemigos debido a sus órdenes. 
Tras un prólogo de enunciado omnisciente y lejano en el que el espectador contempla a un anciano veterano que acude a prestar sus respetos a un cementerio militar, se presenta el desembarco. Este se inicia sin aviso previo, sin presentación de personajes, sin planteamiento de la misión o los preparativos de esta (cosa impensable en el modelo canónico anterior). Este brusco cambio narrativo contribuye a la sorpresa y tensión del público por la ruptura de sus expectativas, condicionadas por las películas bélicas vistas hasta entonces. El contraste estilístico que supone respecto a la enunciación convencional del prólogo también contribuye a alterar emocionalmente al espectador, que debe abandonar el rol pasivo que se le invitó a ocupar en la primera secuencia.

Para transmitirle la sensación fisiológica de estar inmerso en el combate, el cineasta obliga al espectador a asumir dos puntos de vista, entre los cuales se alterna. Ninguno resulta cómodo, ni permite un rol pasivo.

En esta secuencia no hay constancia de ningún personaje que sea operador de guerra, pero la presencia diegética de la cámara es evidente. Se emplea un tratamiento documental (cámara en mano, cuadros desequilibrados, barridos y movimientos inestables, etc.) (figuras 2 y 3 ). La cámara se sumerge y se resguarda de los disparos que se dirigen al punto de vista (figuras 4 y 5), o incluso su lente llega a mancharse de sangre o barro tras las explosiones (figuras 6-8). Como homenaje a los cineastas que filmaron la guerra, Spielberg obliga al espectador a asumir su punto de vista. Le da un lugar en el escenario del combate. Esto le permite compartir la experiencia de Miller, ser su compañero de armas, al verse obligado a visualizar frontalmente la barbarie y enfrentarse al ataque del enemigo junto a él (figuras 2, 3 y 7). Así el espectador participa del combate como lo haría en un videojuego: temiendo que su avatar, y el capitán al que acompaña, "pierdan una vida”, lo que eleva su nivel de tensión. En otras ocasiones el operador de guerra visualiza lateralmente el avance de las tropas o de Miller, lo que también causa tensión (aunque menos, por tener una función más descriptiva), puesto que pierde de vista el origen de la barbarie, el enemigo, y las balas cruzan el cuadro sin que nuestro avatar pueda preverlo, impotente ante los soldados que caen a su alrededor (figura 9). 


\section{Figuras 2 y 3 \\ Cámara en mano, barridos y cuadros desequilibrados}
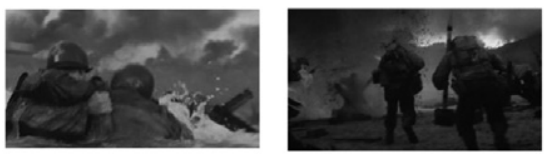

Figuras 4 y 5

Disparos hacia el punto de vista
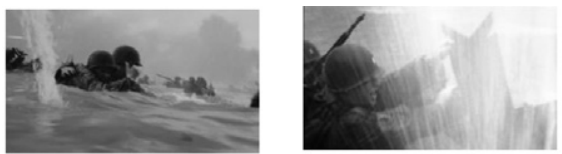

\section{Figuras 6-8}

\section{La lente se mancha de sangre 0 barro}
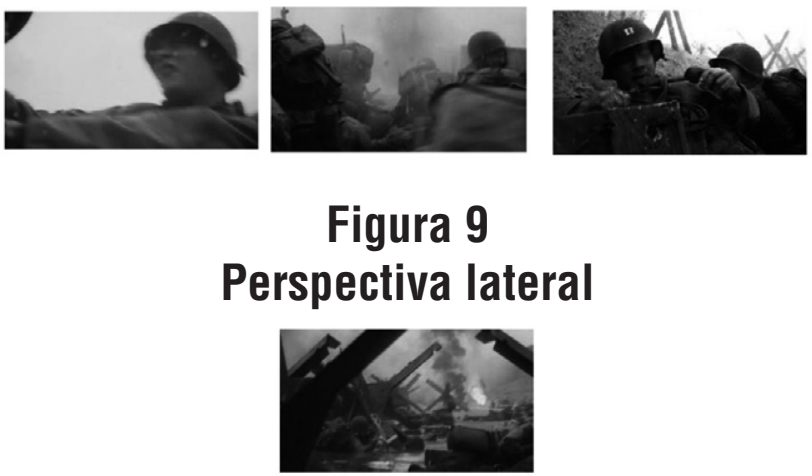

Pero este no es el único rol del espectador. Al mismo tiempo que sigue la acción desde un punto de vista documental, se insertan planos focalizados indirectamente por Miller. Aunque hay planos subjetivos, lo habitual es visualizar al personaje en cuadros cuyos parámetros pretenden expresar sus sensaciones o razonamientos. Así se caracteriza íntimamente al personaje y el espectador no sólo se identifica con Miller en un nivel narrativo, sino que padece sus emociones y comparte su lectura, ya que debe asumir el código focalizado que propone el film para poder interpretarlas.

Los esquemas para señalar la atención del espectador a las emociones y razonamientos de Miller colisionan cualitativamente con los que re- 
producen la acción bélica, presentados desde el punto de vista documental. La lente normal cambia por el teleobjetivo en sus planos o en los de aquello que le afecta, y los cuadros son fijos o de movimientos fluidos (steadicam, travelling o panorámica) (fig. 10). Le presentan frontalmente, incluso mira a cámara en un momento, en lugar de en perspectiva $3 / 4$, trasera o lateral que se emplea en el resto de la secuencia. Su tamaño es todavía más cerrado que en la presentación del combate y se introducen planos subjetivos. La angulación abandona su leve contrapicado y se presenta a la altura de sus ojos en los momentos de mayor intensidad emocional (esto favorece la empatía con él) (fig. 11). Los estados de tensión de Miller se presentan mediante una composición desequilibrada no vinculada a la irregularidad del terreno (fig. 12). Su aturdimiento por explosiones se deduce del ralentizado de la imagen, la supresión del sonido directo y la aparición de un ambiente extradiegético.

\section{Figura 10} Uso del teleobjetivo
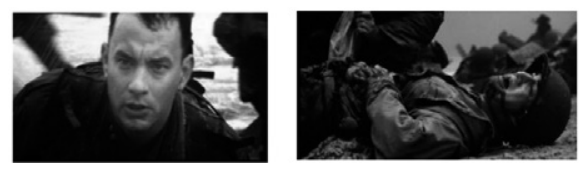

Figura 11

Frontalidad, uso del teleobjetivo y del plano subjetivo
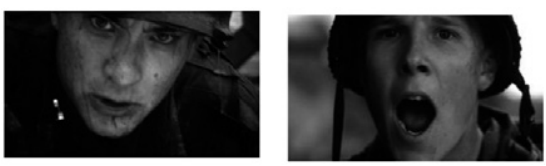

Figura 12

Composición desequilibrada motivada por estado emocional de Miller
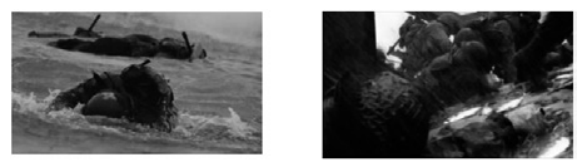
El contraste entre puntos de vista obliga al espectador a adecuar su modo de lectura continuamente. La variación hace que, desde un código naturalista, resulte una experiencia fílmica incómoda, lo cual contribuye a la tensión.

Además, durante 23 minutos, no resulta clara la disposición espacial del combate. Aunque la secuencia transcurre en continuidad directa y se dispone en torno a un eje de dirección marcado, se repiten muy pocas posiciones de cámara. El combate parece en ocasiones una "realización en directo" entre planos tomados por múltiples operadores documentales. Esto obliga al espectador a resituarse ante cada cambio de plano y le dificulta en ocasiones localizar a Miller, lo que incrementa su tensión (figura 13). Además debe recomponer el espacio, ya que los cuadros ofrecen una perspectiva restringida de este (son cerrados y no resulta fácil relacionarlos con otros, al faltar planos de situación). También numerosos recursos acusan su elevado nivel de fragmentación. Muchos cortes de imagen se sincronizan con el sonido de las olas, disparos y explosiones, y se incluyen saltos adelante o atrás (cuadros de diferente tamaño que se suceden sin modificación de perspectiva o angulación) que rompen la fórmula de lectura más cómoda (que obliga a una diferencia de $30^{\circ}$ en la posición de las cámaras para evitar "saltos" perceptivos) (figura 14).

Figura 13

\section{Planos sucesivos de escena $A$ tomados desde múltiples perspectivas}
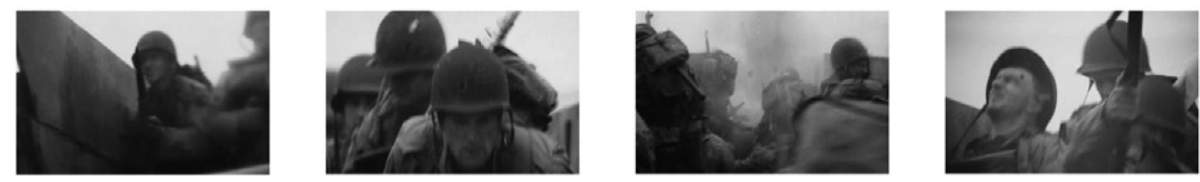

Figura 14

"Salto atrás" desde el punto de vista de Miller
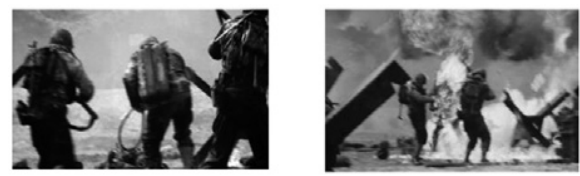
En otros momentos, un único operador sigue a Miller y presenta sus acciones en un solo corte. Este contraste estructural entre escenas de elevado y marcado nivel de fragmentación y otras que transcurren en tiempo fiel tiene un importante efecto rítmico en la velocidad de lectura del espectador. Los fragmentos presentados mediante un único operador de guerra no resultan más lentos, pese a que los planos sean más largos en duración, ya que el contraste con los anteriores conlleva una mayor inmersión del espectador en el contexto de acción. Por unos momentos desaparece la mediación cinematográfica que asocia a la enunciación fragmentada. Esto hace que la identificación emocional con el avatar del operador de guerra y el sujeto al que sigue resulte más intensa y que su sensación temporal no se lentifique (figura 15).

\section{Figura 15 \\ Plano de seguimiento documental individual}

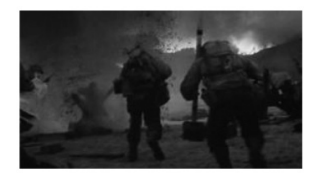

Su velocidad de lectura también se ve condicionada por el estado de ánimo colectivo o de Miller. El ritmo de la secuencia es focalizado, ya que la duración relativa de los planos de cada fragmento se adecúa a la situación emocional de los personajes -salvo en los momentos en los que la duración del plano se debe a subrayar la "actividad" de un único operador cinematográfico-. Las escenas de planos breves, de duración decreciente y de mayor nivel de fragmentación responden a su nerviosismo; lo contrario, a su calma (figura 16 y 17 ).

Figura 16

Escena A. Esquema rítmico focalizado decreciente

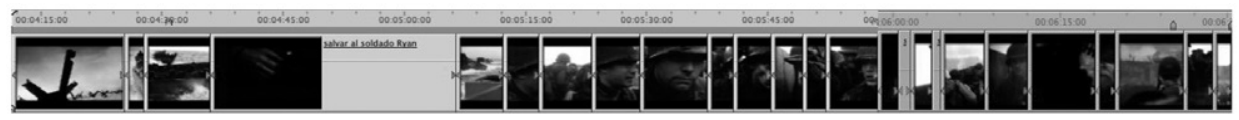




\section{Figura 17 \\ Escena L. Bajo nivel de fragmentación \\ y planos largos en duración}

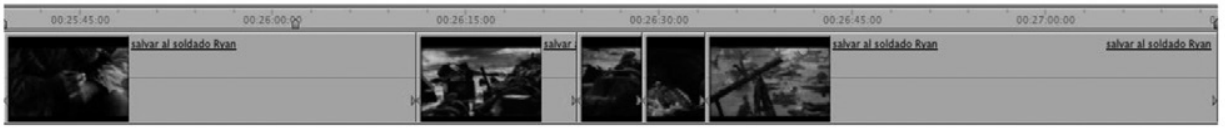

En resumen, el diseño general de la secuencia basado en continuos contrastes estilísticos (combinación de planos de diferente focalización, contraste en nivel de fragmentación y ritmo de las escenas, heterogeneidad y dificultad para la ubicación e interrelación de sus planos) obliga al espectador a adaptar su modo y velocidad de lectura continuamente. Estas estrategias cinematográficas le hacen padecer involuntariamente las sensaciones fisiológicas de un soldado inmerso en el campo de batalla -ya sean las de los operadores de guerra o las del propio Miller- debido a su percepción de múltiples y variados estímulos que se suceden a mucha velocidad, la dificultad para fijar su atención, poder pensar y ubicarse, una tensión variable, etc. Aunque el tempo de la secuencia no es rápido (la duración media de los planos es de casi siete segundos), todo redunda en una sensación rítmica muy alta, por ser compleja de seguir. Esto se corresponde con un permanente estado de intensa tensión.

Para ordenar y clarificar la compleja exposición del episodio, el cineasta divide la larga secuencia en escenas. Estas se detectan por la adopción de un determinado tipo de esquemas estructurales, rítmicos o compositivos que varían, dentro del sistema general de la secuencia -ya planteado-, con el paso al fragmento siguiente. El cambio en la enunciación coincide con un cambio de emplazamiento dentro de la localización y con la ejecución de una nueva orden de Miller tras el fracaso o éxito de la anterior.

Así se incide además en el subtexto de la secuencia: presentar el sentimiento de responsabilidad de un ciudadano obligado a ser soldado y a avanzar para cumplir una misión, pese a los principios éticos de su identidad civil, su verdadero yo. El objetivo que persigue solo lo conoce él -no se nos han expuesto las fases de la misión- y ha de responsabilizarse de los 
medios para conseguirlo y de sus consecuencias. Es el fundamento del desequilibrio entre su identidad civil y su obligación militar. Solo cuando salva a Ryan encajan ambas.

Para señalar el origen de su trauma, sus órdenes delimitan las escenas ante el resultado de la anterior. La A termina con la orden de dejar la barcaza; la $\mathrm{B}$ con su decisión de salir del mar; la $\mathrm{C}$ con la de avanzar playa adentro para guarecer a su tropa ante la masacre; la D con la de arrastrar a un compañero herido hasta un lugar seguro; la $\mathrm{E}$ con la de abandonar ese cuerpo ya muerto y guarecerse tras una duna; la $F$ se inicia con su mandato de sacar de la playa a Wade (el médico) y llevarlo a su posición, y termina cuando ordena que recojan las armas de los muertos o heridos y se empleen las pértigas explosivas; la G se corresponde a su empleo y termina con la orden de avanzar hasta la posición que cubre una ametralladora enemiga; la $\mathrm{H}$ se aparta excepcionalmente de Miller y presenta el desenlace de la situación de Wade (se queda en la playa atendiendo heridos); la I presenta la orden de Miller de cruzar a una posición desde donde abatir la ametralladora -dos oleadas de soldados mueren en el intento hasta lograr el objetivo-; la $\mathrm{J}$ muestra las operaciones y órdenes de Miller y de su subalterno Sizemore para tomar la posición enemiga y su reacción ante la barbarie de los suyos. Las escenas $\mathrm{K}$ y L sirven como coda al episodio: destacan la reacción de los protagonistas a lo que han vivido. La última muestra la reacción de Miller y la lectura del cineasta: aquí se emplea por primera y única vez un punto de vista omnisciente y acompañamiento musical para que el espectador reflexione sobre el efecto de la guerra.

Debido al difícil contexto de lectura que se presenta al espectador, el cineasta debe destacar los momentos destinados a acusar el subtexto emocional de la secuencia (el origen del trauma de Miller) y facilitar su interpretación. En estos momentos, además de emplear el código definido para caracterizar íntimamente a Miller -ya señalado-, se introducen determinados esquemas que se emplean de modo restrictivo para acusar su intención simbólica. Suponen un contraste con el estilo general de la secuencia, y así el espectador detecta que en estos momentos la configuración de los planos o fragmentos tiene una intención comunicativa que va más allá de 
la reproducción del combate histórico o las sensaciones del soldado asociadas a él: destacan el conflicto que supone para Miller ordenar o ejecutar protocolos militares contrarios a sus principios éticos y su sentimiento de culpa. El espectador debe realizar un esfuerzo añadido para interpretar el valor simbólico de su configuración.

Para facilitar la decodificación de estos momentos, el cineasta recurre a esquemas gráficos, rítmicos y estructurales específicos que se repiten para presentar contenidos diferentes a lo largo del episodio. La redundancia en su configuración permite al espectador detectar que se relacionan con un mismo motivo emocional. La primera aparición de cada esquema simbólico es de fácil interpretación. La configuración específica del plano complementa el sentido de un contenido ya asociado al trauma, de tal modo que cuando se emplee por segunda vez aplicado a un contenido de lectura menos evidente, su decodificación esté condicionada por su empleo previo. El episodio "educa" al espectador en su lenguaje.

El uso del tilt vertical desde una perspectiva frontal -de plano detalle de un elemento a primer plano del rostro- es uno de estos esquemas asociados al trauma de Miller. La primera vez que aparece presenta el temblor de su mano (figura 18). Reaparece en la escena C, cuando recoge su casco que chorrea la sangre de sus hombres, se lo pone y la sangre mancha su rostro. Sin más movimientos de cámara en la escena, su lectura permite comprender que asume su culpa ante lo que ve -baña su rostro de sangre(figura 19). Finalmente, en la secuencia L, un nuevo tilt presenta la reactivación de su temblor al contemplar los cadáveres de la orilla, que percibe, en parte, como resultado de sus decisiones (figura 20).

\section{Figura 18}

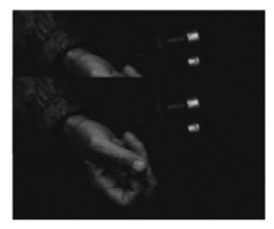

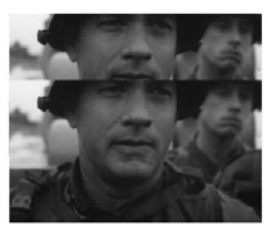

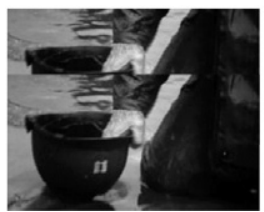

Figura 19

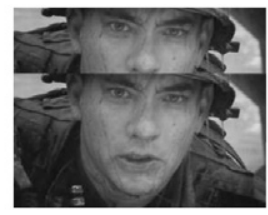




\section{Figura 20 \\ Tilt de escena L}
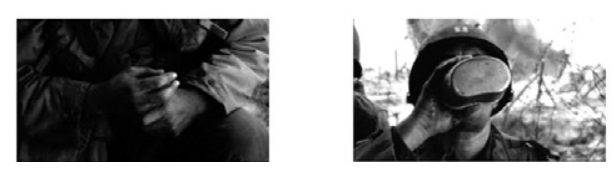

En algunos momentos la composición de los cuadros resulta especialmente significante. Se presentan elementos por delante o detrás del capitán que añaden sentido -simbolizan el sentimiento de culpa que abruma a Miller-, por suponer una colisión interna en la puesta en escena del cuadro. Esto ocurre en el momento previo a ponerse el casco en la escena $\mathrm{C}$, cuando asimila lo que está viendo. Su estatismo choca con el dinamismo del término posterior, donde se aprecia arder a los hombres que huyen de una barcaza en llamas. La composición hace coincidir el fuego con la posición de su cabeza, lo que sugiere que su "mente está ardiendo" (figura 21). Este recurso simbólico se vuelve a emplear en la escena $L$ en el plano previamente descrito. Al fondo se aprecia una densa nube de humo negro que coincide con su cabeza. La tensión se ha reducido, pero el trauma de la muerte de sus hombres sigue ahí (figura 22). En la escena I, cada vez que ve cruzar por delante de él a los hombres a los que ha dado una orden que implica una muerte segura, se repite un primer plano del capitán por el que cruzan en primer término los pies de sus soldados (figura 23). Cuando cruza Jackson, su compañero, Miller abandona ese lugar "de muerte”, quizás por superstición, lo que carga los planos anteriores de un fuerte sentido simbólico.

Figura 21 Valor simbólico de último

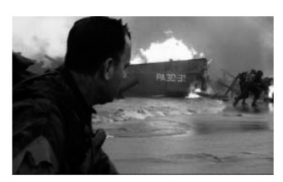

Figura 22 Valor simbólico de último término. Escena L

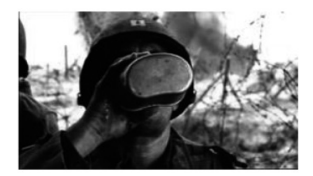

Figura 23

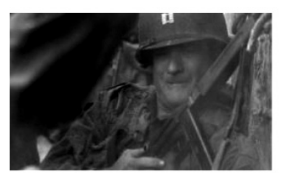


También se altera el tratamiento fotográfico de algunos planos respecto al habitual en la secuencia: su contraste y falta de saturación es mayor. Se aplica en la escena F, en el plano que presenta la orden de Miller de quitar las armas de heridos y muertos (figura 24). Lo mismo ocurre en la secuencia I cuando da la orden a las oleadas de soldados de cruzar hacia la ametralladora (figura 25). Destaca el conflicto que supone para el personaje dar una orden contraria a sus principios éticos.

Figura 24

\section{Tratamiento fotográfico expresivo. Escena $F$}

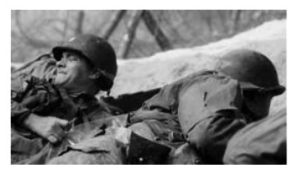

Figura 25

Tratamiento fotográfico

expresivo. Escena I

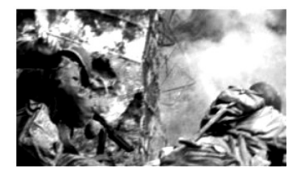

Otro modo de destacar el sentimiento de culpa de Miller a través del tratamiento fotográfico es mediante la aparición de estelas blancas en determinados planos de las escenas G, Iy J. Surgen de la posición de soldados muertos o heridos. Aunque puedan justificarse por la visión alterada que tendría un soldado tras tanto tiempo combatiendo, la coincidencia compositiva con los cadáveres sugiere que simbolizan su alma: lo que Miller carga en su conciencia. La aparición de estelas rojas en los planos que presentan el asesinato de dos soldados alemanes que se rendían en la escena J confirma esta lectura. El plano que presenta la reacción de Miller en esa escena está bañado por estelas de ambos colores, lo que simboliza su sentimiento de culpa por todos los muertos en combate, también por los enemigos asesinados (figura 26).

Figura 26

\section{Estelas blancas en escena $\mathrm{G}$ y estelas blancas y rojas en escena $\mathrm{J}$}
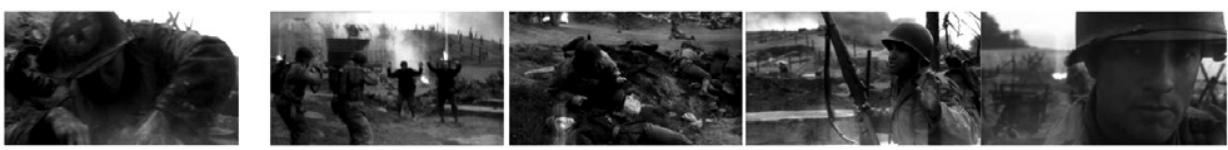
Existe un esquema estructural que se usa de un modo restrictivo en algunas escenas para señalar la causa del trauma de Miller. Las escenas D e I se dividen en tres pulsos dramáticos en los que se visualiza dos veces la misma acción u orden "inmoral" de Miller mediante esquemas gráficos similares, hasta que la tercera vez se resuelve su dilema. En la primera pasa de largo junto a heridos que requieren su ayuda: ya no son útiles al combate, y se destaca mediante la angulación cenital o mediante un iris su falta de reacción, hasta que la tercera vez que alguien requiere su ayuda se pasa a un gran contrapicado. En la segunda, se repite exactamente la planificación del primer pulso en el que "envía soldados al matadero" cuando lo hacen por segunda vez; al cruzar Jackson los esquemas varían.

La yuxtaposición es otro esquema estructural que se reserva para señalar el motivo de su trauma: la responsabilidad de Miller sobre la supervivencia de sus soldados. En la escena A se presenta mediante este esquema el temor de diferentes soldados ante el combate que se avecina, en la B se presenta su muerte por ahogamiento, en parte, por la orden de Miller de tirarse al agua. En la L, la yuxtaposición presenta los cadáveres que se acumulan en la orilla. En todos ellos se abandona el ritmo focalizado habitual por uno regular, en el que cada plano presenta la misma duración.

\section{Conclusión}

Los resultados del análisis confirman que el diseño de la secuencia se basa en la heterogeneidad y el contraste estilístico entre esquemas compositivos y de montaje, cuyo uso es repetitivo y restrictivo según el motivo emocional o temático al que sirven. Esto confirma el argumento de King, Dancyger y Stam, y el de algunos cineastas contemporáneos del género de acción, de que en las secuencias más espectaculares se recurre a estrategias de Eisenstein para manipular eficazmente al espectador. Es una manipulación emocional e ideológica, no necesariamente política. Se emplean aunque se parta de una enunciación de tipo analítico en continuidad.

Unos esquemas sirven para reproducir la experiencia y conseguir la participación vicaria del espectador, su inmersión; otros, para lograr su compromiso emocional con el personaje; otros específicos sirven para la 
reproducción del trauma y sus causas. El sentido de la secuencia resulta así fácil de percibir gracias al contraste estilístico, pero no es fácil de comprender, puesto que en un primer visionado el espectador no puede realizar un análisis preciso. Aunque el combate histórico tiene un protagonismo esencial, sólo sirve de contexto para la caracterización emocional y psicológica de Miller, afectado por algo que tardará en explicarse verbalmente (secuencia 18, en la Iglesia, donde confiesa su cargo de conciencia, y secuencia 23, tras la liberación del prisionero alemán, donde da cuenta de por qué salvar a Ryan: retornar a su identidad civil).

El diseño expresivo de esta secuencia al servicio de motivos emocionales y temáticos, el uso de los esquemas y de la colisión cualitativa, le han señalado al espectador los referentes precisos para que, en monólogos escuetos posteriores, pueda comprender el conflicto íntimo del personaje, como cuando un veterano se solidariza con el relato traumático de otro. Así, un género marcado por su uso propagandístico anterior hace menos evidentes sus intenciones y permite ampliar su público objetivo. Todo espectador, crítico o no con el mensaje de $S P R$, puede empatizar con el hombre al que se dibuja mediante este estilo audiovisual.

\section{Referencias}

Ambrose, S. E. (1998). The kids who changed the World. Newsweek.

Aumont, J. \& Marie, M. (1988/1990). Análisis del film. Barcelona: Paidós Comunicación, cine 42 .

Auster, A. \& Quart, L. (1988). How the war was remembered: Hollywood and Vietnam. Nueva York: Praeger.

Basinger, J. (1986). The World War II combat film. Anatomy of a genre. Nueva York: Columbia University Press.

Basinger, J. (1994). American cinema: One hundred years offilmmaking. Nueva York: Rizzoli. 
Biesecker, B. (2002). Remembering World War II: The rhetoric and politics of national commemoration at the turn of the 21 st century. Quarterly of Journal Speech, 88(4), 393-409.

Bodnar, J. (2001). Saving Private Ryan and postwar memory in America. The American Historical Review, 106(3), 805-817.

Bourke, J. (2004). Introduction: 'Remembering'War. Journal of Contemporary History, 39(4), 473-485.

Cohen, E. (1999). What combat does to men. Current, 412, 35-39.

Cole, T. (2002). Scales of memory, layers of memory: Recent works on memories of the Second World War and the Holocaust. Journal of Contemporary History, 37, 129-138.

Dancyger, K. (2007). Film and video editing. Burlington: Focal press.

Ehnrenhaus, P. (2001). Why we fought: Holocaust memory in Spielberg's Saving Private Ryan. Critical Studies in Communication, 18(3), 321-337.

Eisenstein, S. M. (1924). The montage of film attractions. En Taylor, R. (Ed.), Selected Works. Writings 1924-1934 (39-59). Londres: British Film Institute.

Eisenstein, S. M. (1929/1999). El principio cinematográfico y el ideograma. En Teoría y técnica cinematográficas (83-101). Madrid: Ediciones Rialp.

Eisenstein, S. M. (1934). El lenguaje cinematográfico. En Taylor, R. (Ed.), Writings, 1922-1934 (285-294). Londres: I. B. Tauris \& Co. Ltd.

Eisenstein, S. M. (1934/1999). Del teatro al cine. En Teoría y técnica cinematográficas (57-73). Madrid: Ediciones Rialp. 
Eisenstein, S. M. (1937). Montaje 1937. En Glenny, M. \& Taylor, R. (Eds.), Hacia una teoría del montaje, 1 (37-87). Barcelona: Paidós Comunicación 115 cine.

Eisenstein, S. M. (1939/1970). La unidad orgánica y lo patético en la composición de El acorazado Potemkin. En Reflexiones de un cineasta (111-123). Barcelona: Lumen.

Gates, P. (2005). Fighting the good fight: The real and the moral in the contemporary Hollywood combat film. Quarterly Review of Film and Video, 22, 297-310.

Hasian, M. (2001). Nostalgic longings, memories of the "Good War" and cinematic representations in Saving Private Ryan. Critical Studies in Media Communication, 18(3), 338-358.

King, G. (2000/ 2009). Spectacular narratives. Hollywood in the age of the blockbuster. Londres: I. B. Tauris \& Co.

King, G. \& Krzywinska, T. (2002). Screenplay. Cinema/videogames/interfaces. Londres \& Nueva York: Wallflower Press.

Klien, S. A. (2005). Public character and the simulacrum: The construction of the soldier patriot and citizen agency in Black Hawk Down. Critical Studies in Media Communication, 22(5), 427-449.

Lagrou, P. (2000). The legazi of Nazi ocupation. Patriotic memory and national recovery in western Europe, 1945-1965. Cambridge: Cambridge University Press.

Leed, E. (2000). Fateful memories: Industrialized war and traumatic neuroses. Journal of Contemporary History, 35(1), 85-100.

Muruzábal, A. (2007). La representación cinematográfica del regreso. El cine de veteranos como expresión privilegiada del género bélico. (Tesis doc- 
toral en Comunicación no publicada.) Universidad de Navarra, Pamplona, España.

Muruzábal, A. \& Grandío, M. M. (2009). La representación de la guerra en la ficción televisiva norteamericana contemporánea. Mediaciones Sociales, 5(2), 63-83.

Pérez, J. C. (2012). Salvar al soldado Ryan con 300 espartanos: historia, memoria, mito. Revista comunicación, 10(1), 800-816.

Sánchez- Biosca, V. (1996). El montaje cinematográfico, teoría y análisis. Barcelona: Ediciones Paidós Ibérica.

Schatz, T. (2002). Old War/New War: Band of Brothers and the revival of war film. Film \& History, 32(1), 74-78.

Stam, R. (2000/2001). Teorías del cine. Barcelona: Paidós Comunicación.

Sugimoto, M. (2000). Traumatic Modernity: Contested sites of national memory in Saving Private Ryan, Afterlife, and Rashomon. En Twelfth SCA/AFA Conference on Argumentation 2001, 2 (643- 651). Alta: National Communication Association.

Walker, J. (2004). The vicisitudes of traumatic memory and the postmodern history film. En Kaplan, A. \& Wang, B. (Eds.), Trauma and cinema. Cross-cultural explorations (123-144). Hong Kong: Hong Kong University Press.

Wetta, F. \& Novelli, M. (2003). "Now a major motion picture”: War films and Hollywood's new patriotism. Journal of military History, 67(3), 861-882.

Winter, J. (2001). Film and the matrix of memory. The American Historical Review, 106(3), 857-864. 


\section{Videografía}

Apple, W. (productor y director) (2004). The Cutting Edge. The Magic of Movie Editing [documental]. Estados Unidos: TCEP, NHK, Kuleshov Shoot y BBC.

Cowen, M. \& Richter, W. (productores), Cowen, M. (director) (2001). We Stand Alone Together [documental]. Estados Unidos: Cowen/Richter Productions, DreamWorks y HBO.

Eastwood, C., Lorenz, R. \& Spielberg, S. (productores), Eastwood, C. (director) (2006). Letters from Iwo Jima [película]. Estados Unidos: DreamWorks SKG, Warner Bros., Malpaso Productions.

Eastwood, C., Lorenz, R. \& Spielberg, S. (productores), Eastwood, C. (director) (2006). Flags of Our Fathers [película]. Estados Unidos: DreamWorks SKG, Warner Bros., Amblin Entertainment.

Eisenstein, S. M. (director) (1925). El acorazado Potemkin [película]. URSS: Goskino.

Hanks, T. \& Spielberg, S. (productores) (2001). Band of Brothers [serie de televisión]. Estados Unidos: DreamWorks SKG, DreamWorks Television, Home Box Office.

Spielberg, S., Bryce, I. \& Gordon, M. (productores), Spielberg, S. (director) (1998). Saving Private Ryan [película]. Estados Unidos: DreamWorks SKG, Paramount Pictures, Amblin Entertainment.

\section{Notas}

La duración media de los planos se obtiene de la fórmula: duración de la secuencia en segundos (1375) dividida entre el número de cortes (202). 